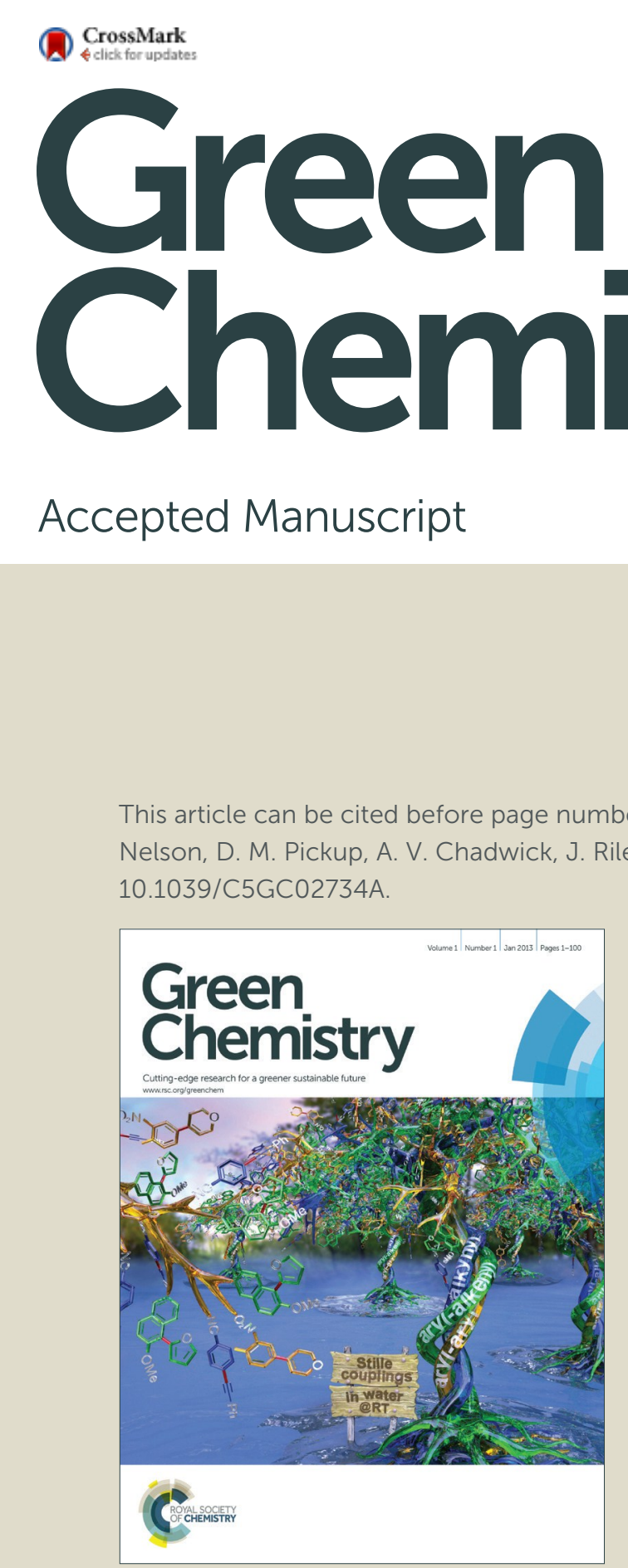

This article can be cited before page numbers have been issued, to do this please use: C. G. Poll, G. Nelson, D. M. Pickup, A. V. Chadwick, J. Riley and D. Payne, Green Chem., 2016, DOI:

\section{Green Chemistry}

This is an Accepted Manuscript, which has been through the Royal Society of Chemistry peer review process and has been accepted for publication.

Accepted Manuscripts are published online shortly after acceptance, before technical editing, formatting and proof reading. Using this free service, authors can make their results available to the community, in citable form, before we publish the edited article. We will replace this Accepted Manuscript with the edited and formatted Advance Article as soon as it is available.

You can find more information about Accepted Manuscripts in the Information for Authors.

Please note that technical editing may introduce minor changes to the text and/or graphics, which may alter content. The journal's standard Terms \& Conditions and the Ethical guidelines still apply. In no event shall the Royal Society of Chemistry be held responsible for any errors or omissions in this Accepted Manuscript or any consequences arising from the use of any information it contains. 


\title{
Electrochemical Recycling of Lead from Hybrid Organic-Inorganic Perovskites using Deep Eutectic Solvents
}

\author{
Christopher G. Poll ${ }^{1}$, Geoffrey W. Nelson ${ }^{1}$, David M. Pickup ${ }^{2}$, Alan V. Chadwick ${ }^{2}$, D. Jason Riley ${ }^{1}$, and \\ David J. Payne ${ }^{1^{*}}$ \\ ${ }^{I}$ Department of Materials, Imperial College London, South Kensington, London, SW7 2AZ, United Kingdom \\ ${ }^{2}$ School of Physical Sciences, University of Kent, Canterbury, Kent CT2 7NH, United Kingdom
}

The emerging field of lead-based hybrid organic-inorganic perovskite (HOIP) photovoltaic devices has attracted a great deal of attention due to their very high conversion efficiencies and straightforward fabrication methods. Unfortunately, a major obstacle to commercialization remains the high toxicity of lead. Whilst to date the focus has been on understanding and improving device performance, there has been no reported effort to develop methods to recover and recycle the lead from these materials. In this work we demonstrate a simple, low-cost and environmentally friendly method of recycling lead from HOIP photovoltaics by dissolution and selective electrodeposition using a deep eutectic solvent. We demonstrate that up to $\mathbf{9 9 . 8 \%}$ of the lead is removed from the solvent. The results presented here provide a viable solution to lead-based HOIP photovoltaic recycling, and also open the possibility for providing an alternative method to conventional smelting in the recovery and recycling of different lead-based energy materials. 


\section{Introduction}

Lead and lead compounds have been utilised for thousands of years, finding wide-spread use by the ancient Romans for a number of applications including plumbing and cookware. ${ }^{1}$ Nowadays the use of lead is primarily in the area of energy applications (Figure 1(a)-(b)), and predominantly due to the lead acid battery, ${ }^{2}$ but also as tetra-ethyl lead in "leaded" petrol, ${ }^{3}$ and lead telluride used in thermoelectric generators. ${ }^{4,5}$ Recently lead has found further use as a key energy material in next-generation hybrid organic-inorganic perovskite (HOIP) photovoltaics (PVs), and has subsequently generated a huge amount of scientific interest. ${ }^{6-8}$ The principal HOIP material, methylammonium lead triiodide $\left(\mathrm{MAPbI}_{3}\right)$, has shown great promise as a low-cost, high-efficiency alternative to silicon-based PV technology. ${ }^{9-12}$ The alternative formamidinium lead triiodide $\left(\mathrm{FAPbI}_{3}\right)$, whilst being the subject of fewer studies than $\mathrm{MAPbI}_{3}$, it has demonstrated very promising properties for HOIP PV applications due it having a narrower band gap than $\mathrm{MAPbI}_{3} \cdot{ }^{13-15}$ The mixed halide perovskites $\left(\mathrm{MAPbI}_{3-\mathrm{x}} \mathrm{Cl}_{\mathrm{x}}\right)$ have been shown to possess good stability and are proving to be a popular choice of material for HOIP PV applications. ${ }^{6,12,16-18}$

A major challenge facing HOIP PV is the toxicity and environmental impact of lead. ${ }^{7,19}$ The toxic effects of lead have been well documented, dating back to the second century $\mathrm{BC},{ }^{20}$ and more recently an increased blood lead content in children has been linked to intellectual impairment, ${ }^{21}$ and an increase in juvenile delinquent behaviour. ${ }^{22,23}$ Previous studies highlighted in Figure 1 show links between total lead usage and average blood lead levels (c) and somewhat controversially, rates of murder (d). Globally the primary source of lead waste is from the lead acid battery, which is recycled (like most lead-products) by high temperature smelting. An average concentration of lead in the blood of children who live in the surrounding areas of battery smelting plants in developing countries has been measured at $19 \mathrm{~g} \mathrm{dl}^{-1}$, a value about 13 times higher than the average in children in the U.S. ${ }^{24}$ It is clear that a non-smelting route to recycling lead from HOIP PV must be developed.

In this work we present the application of a deep eutectic solvent (DES) to the recycling of lead-based HOIP PV materials by a clean, low-cost, electrochemical method. DESs are an emerging class of ionic solvent which have seen increasing popularity over the past decade, ${ }^{25,26}$ and have shown excellent capability for the dissolution of metal oxides and salts ${ }^{27,28}$ and electrodeposition of various metals, ${ }^{29}$ demonstrating a degree of re-usability, ${ }^{30-32}$ as well as being considered environmentally friendly. ${ }^{33}$ The DES used in this study is comprised of choline chloride $(\mathrm{ChCl})$ and ethylene glycol $(\mathrm{EG})$, which is demonstrated to easily dissolve $\mathrm{MAPbI}_{3}, \mathrm{FAPbI}_{3}$ and $\mathrm{MAPbI}_{3-\mathrm{x}} \mathrm{Cl}_{\mathrm{x}}$ before electrodeposition of the speciated lead from the solvent. The advantage of a DES over aqueous solvents is the reduction of risk of waste solution being introduced to the water supply, as well as the need not to use volatile organic solvents and concentrated acids. ${ }^{34}$ Furthermore, using an electrochemical process significantly reduces the environmental footprint of high-temperature smelting. A schematic of this process is shown in Figure 2. 


\section{Materials and Methods}

\subsection{Substrate Preparation for HOIP Films.}

$\mathrm{TiO}_{2}$ thin films were formed on fluorine-doped $\mathrm{SnO}_{2}$ (FTO) substrates using sol-gel principles, as developed elsewhere. ${ }^{44,45}$ The FTO substrates were cleaned by sonication in isopropanol for 5 minutes, and dried with $\mathrm{N}_{2}$ gas. A piece of tape covered approximately $1 \mathrm{~cm}^{2}$ of the end of the substrates prior to application of a $\mathrm{TiO}_{2}$ thin film to ensure a controlled coating area was used in each experiment and that the entire film could subsequently be dipped into the DES. A solution with $1 \mathrm{M} \mathrm{Ti(IV)}$ isopropoxide (Sigma-Aldrich) in $4 \mathrm{ml}$ acetic acid (Sigma-Aldrich) and $2.5 \mathrm{ml}$ methoxymethanol (Sigma-Aldrich) was prepared. With a spin-coater set to $500 \mathrm{rpm}$ for 15 seconds and $3000 \mathrm{rpm}$ for 45 seconds, ethanol was first spin-coated onto the FTO substrates. At the same setting, the Ti(IV) isopropoxide solution was spin-coated onto the FTO substrates. The piece of tape was then removed and the substrates annealed at $600^{\circ} \mathrm{C}$ for 60 minutes in a muffle furnace (ramp $2.5^{\circ} \mathrm{C} / \mathrm{min}$.). The $1 \mathrm{~cm}^{2}$ tape coating was replaced on the substrate prior to the addition of HOIP thin films.

\subsection{DES Preparation.}

DES mixtures were prepared by mixing $\mathrm{ChCl}$ ( $\geq 98 \%$, Sigma-Aldrich) and $\mathrm{EG}(\geq 99.5 \backslash \%$, Sigma-Aldrich) in a 1:2 molar ratio and heating and stirring at $60^{\circ} \mathrm{C}$ using a hotplate until a clear and colourless liquid was formed. The specific quantities of the constituents for each experiment are detailed in the text.

\subsection{Thin Film HOIP Synthesis and Dissolution.}

Methylammonium iodide $\left(\mathrm{CH}_{3} \mathrm{NH}_{3}{ }^{+} \mathrm{I}^{-}\right)$was prepared by adapting the methods of Eperon et al. ${ }^{18}$ Hydroiodic acid (HI, $57 \mathrm{wt} / \%$ in water, Sigma-Aldrich) was added dropwise to methylamine (33 wt $\% \%$ in ethanol, SigmaAldrich) whilst stirring at room temperature. It was dried in a rotovaporator under vacuum at $60^{\circ} \mathrm{C}$. The product was washed with diethyl ether (Sigma-Aldrich) and dried overnight in a vacuum oven to form a white powder. This compound was then stored in a desiccator. Formamidium iodide $\left(\mathrm{HC}\left(\mathrm{NH}_{2}\right)_{2}{ }^{+} \mathrm{I}^{-}\right)$was prepared by adapting the method contained within the supplementary information of the recent work of Eperon et al. ${ }^{13} \mathrm{~A}$ mixture of formamidinium acetate (Sigma-Aldrich) powder in $2 \times$ molar excess of hydroiodic acid was stirred for 10 minutes at $50^{\circ} \mathrm{C}$, and then dried at $60^{\circ} \mathrm{C}$ using a rotovaporator. It was then washed with diethyl ether and recrystallised once with ethanol. The product was dried overnight in a vacuum oven and stored in a desiccator until required.

To form the HOIP thin films, three precursor solutions were mixed in ambient conditions with anhydrous dimethyl sulfoxide (DMSO) as the solvent. ${ }^{18,46}$ As recycling of the HOIP, not performance, is the crucial aspect of this work it was deemed sufficient to prepare these HOIPs in ambient conditions. ${ }^{47}$ The nonstoichiometric $\mathrm{Cl}-\mathrm{MAPBI}_{3}$ was formed as per Eperon et al ${ }^{18}$ with methylammonium iodide dissolved with lead(II) chloride in a $3: 1$ ratio, and having concentrations of $2.64 \mathrm{M}$ and $0.88 \mathrm{M}$ respectively. The $\left(\mathrm{CH}_{3} \mathrm{NH}_{3}{ }^{+}\right) \mathrm{PbI}_{3}$ precursor was formed by mixing methylammonium iodide with $\mathrm{Pb}$ (II) iodide in a $1: 1$ ratio to 
form a $0.88 \mathrm{M}$ precursor solution. ${ }^{13}$ The $\mathrm{HC}\left(\mathrm{NH}_{2}\right)_{2}{ }^{+} \mathrm{PbI}_{3}$ precursor was made by mixing formamidinium iodide with lead(II) iodide in a 1:1 ratio to form a $0.88 \mathrm{M}$ solution. ${ }^{13}$ Each precursor was stirred at $70^{\circ} \mathrm{C}$ for 30 minutes prior to spin-coating. In all three cases, $60 \mu \mathrm{l}$ of precursor was spread over the $\mathrm{TiO}_{2}-\mathrm{FTO}$ substrate spin-coated at $500 \mathrm{rpm}$ for 15 seconds and $3000 \mathrm{rpm}$ for 45 seconds. After spin-coating the tape was removed. The Cl-MAPBI 3 and $\mathrm{MAPBI}_{3}$ were then annealed in air at $100^{\circ} \mathrm{C}$ for 1 hour, whilst the FAPI annealed in air at $150^{\circ} \mathrm{C}$ for 1 hour. The as-prepared HOIP thin films were placed immediately into the DES solutions or studied using x-ray diffraction (XRD) within 10 minutes of preparation. The samples prepared for scanning electron microscopy (SEM) were stored overnight in a desiccator prior to study. To study the stripping of the HOIP films $\left(\mathrm{MAPbI}_{3}, \mathrm{FAPbI}_{3}, \mathrm{MAPbI}_{3-\mathrm{x}} \mathrm{Cl}_{\mathrm{x}}\right)$ from the $\mathrm{TiO}_{2}$ coated FTO substrate, the HOIP films were held in the 1:2 molar ratio $\mathrm{ChCl}$ :EG DES, whilst maintained at $60^{\circ} \mathrm{C}$, for 30 minutes to dissolve the HOIP layer. Following the stripping and dissolution of the HOIP material, the samples were studied with XRD and SEM to demonstrate the successful removal of the HOIP layer.

\subsection{Powdered HOIP Synthesis and DES Electrochemistry.}

In order to synthesise HOIP powder, to provide the quantities required for higher concentrations of dissolved HOIP in the DES, the precursor solutions were dried overnight in a low humidity environment. This was done by freshly preparing precursor solutions, as previously, and placing the heated precursor solutions into a three-neck round bottom flask, which was then stirred using a magnetic stirrer bar. A rubber septum was placed over the middle neck, with greased valves placed over the outside necks. One valve was connected to an $\mathrm{N}_{2}$ gas source and the other to a gas bubbler filled with silicon oil. The solution was heated to the respective annealing temperature of the HOIPs which had two effects: first, the DMSO evaporated out of solution; second, all the HOIPs crystallised into a solid black crystal which was capable of arresting the movement of the magnetic stir bar. The gas was allowed to flow for the duration of the evaporating and annealing process to minimise the humidity and prevent powder degradation. This powder was placed immediately into the DES at the desired concentration after breaking the nitrogen-rich environment.

DESs containing powdered HOIP were prepared by adding the powder to the ChCl-EG DES, whilst being maintained at $60^{\circ} \mathrm{C}$ with EG:ChCl:HOIP mole ratios of 2:1:0.00057. The DESs were heated and stirred until the HOIP material was fully dissolved. Three electrode cells were prepared using an $\mathrm{IrO}_{2}$ coated Ti mesh counter electrode and $\mathrm{Ag}$ wire quasi-reference electrode and a working electrode of tin-doped indium oxide (ITO) (8-12 $\Omega$ /square, Sigma-Aldrich). The ITO working electrodes were ultrasonically cleaned in acetone, isopropanol and deionised water and dried with an $\mathrm{N}_{2}$ gas flow prior to placing into the DES solutions. For each electrochemical measurement fresh working electrodes were used. Cyclic voltammogram's (CVs) and potentiostatic electrochemical experiments were controlled using an Ivium CompactStat potentiostat with the DES maintained at $60^{\circ} \mathrm{C}$. 


\subsection{Complete Pb Extraction from Solution.}

The complete extraction of $\mathrm{Pb}$ from DES solutions containing dissolved HOIP powder was demonstrated by preparing DES solutions of each HOIP powder $\left(\mathrm{MAPbI}_{3}, \mathrm{FAPbI}_{3}, \mathrm{MAPbI}_{3-\mathrm{x}} \mathrm{Cl}_{\mathrm{x}}\right)$ dissolved in a ChCl-EG DES, as described previously. The solutions were prepared containing the $\mathrm{EG}, \mathrm{ChCl}$ and HOIP in mole ratios of 2:1:0.00057 with a total volume of $40 \mathrm{ml}$. From this $10 \mathrm{ml}$ was extracted prior to the electrodeposition for inductively coupled plasma mass spectrometry (ICP-MS) measurement of the pre-extraction $\mathrm{Pb}$ concentration. The remaining $30 \mathrm{ml}$ of each HOIP-DES were maintained at $60^{\circ} \mathrm{C}$ using a hotplate and incorporated into a three electrode cell using an $\mathrm{IrO}_{2}$ coated $\mathrm{Ti}$ counter electrode, $\mathrm{Ag}$ wire quasi-reference electrode and $\mathrm{Pb}$ foil working electrode. In each case the $\mathrm{Pb}$ foil (99.998\% purity, Alfa Aesar) was prepared with a working area of $7.5 \mathrm{~cm}^{2}$, polished with 1000 grit $\mathrm{SiC}$ paper, soaked and rinsed in isopropanol and dried with $\mathrm{N}_{2}$ gas prior to insertion into the DES solutions. A fresh $\mathrm{Pb}$ foil was used for each of the three $\mathrm{Pb}$ extractions. The electrochemical cell was controlled using an Ivium CompactStat potentiostat, with a potential of $-0.9 \mathrm{~V}$ vs $\mathrm{Ag}$ applied for 120 hours to drive the deposition of the dissolved $\mathrm{Pb}$ onto the $\mathrm{Pb}$ foil working electrode. Following the complete extraction of $\mathrm{Pb}$ from each HOIP-DES solution, the concentration of $\mathrm{Pb}$ in each solution was measured with the ICP-MS by the Chemical Analysis Facility at the University of Reading.

\subsection{XRD and SEM Characterisation.}

XRD patterns were measured using Panalytical X'Pert Pro and Bruker D2 Phaser diffractometers. SEM images were recorded with a JEOL JSM 5610 LV electron microscope and HR-SEM images were recorded using a LEO Gemini 1525 electron microscope.

\subsection{Extended X-ray Absorption Fine Structure (EXAFS).}

EXAFS measurements of the HOIP-DESs were undertaken at beamline B18 at the Diamond Light Source, Harwell, UK. The EXAFS samples were held in polytetrafluoroethylene (PTFE) cells with Kapton foil windows. The EXAFS spectra were recorded using the $\mathrm{Pb} \mathrm{L}_{3}$ edge. The samples were placed in the beam path with a fluorescence detector at $90^{\circ}$ to the beam. A hot air gun, set to $70^{\circ} \mathrm{C}$, was positioned around $20 \mathrm{~cm}$ from the samples, gently warming them above ambient conditions to prevent any formation of solid crystals in the liquids. Between 27 and 36 spectra were collected from each sample. These were summed, calibrated and background subtracted using the program Athena. ${ }^{48}$ The resulting spectra were fitted using the program Artemis to yield information on the speciation of the dissolved HOIP in the DES. ${ }^{48}$ The passive electron reduction factor $S_{0}$ was set at $0.83 .{ }^{49}$ A $k$-range of 3-12 $\AA^{-1}$ and a R-range of 1.8-3.4 $\AA$ was used. The quality of the fits are reported in terms of the R-factor which is defined as:

$$
R=\sum_{i=1}^{N_{p t s}} \frac{\left[\operatorname{Im}\left(\chi_{\text {dat }}\left(R_{i}\right)-\chi_{t h}\left(R_{i}\right)\right)\right]^{2}+\left[\operatorname{Re}\left(\chi_{\text {dat }}\left(R_{i}\right)-\chi_{\text {th }}\left(R_{i}\right)\right)\right]^{2}}{\left[\operatorname{Im}\left(\chi_{\text {dat }}\left(R_{i}\right)\right)\right]^{2}+\left[\operatorname{Re}\left(\chi_{\text {dat }}\left(R_{i}\right)\right)\right]^{2}}
$$

where $\chi_{\text {dat }}$ is the experimental data, $\chi_{\mathrm{th}}$ is the calculated fit and $\mathrm{N}_{\mathrm{pts}}$ is the number of data points. 


\section{Results and Discussion}

\subsection{Solvation of Hybrid Organic Inorganic Perovskite Films}

Films of each of the HOIPs $\left(\mathrm{MAPbI}_{3}, \mathrm{FAPbI}_{3}\right.$ and $\left.\mathrm{MAPbI}_{3-\mathrm{x}} \mathrm{Cl}_{\mathrm{x}}\right)$ on $\mathrm{TiO}_{2}$ coated FTO were placed in $0.18 \mathrm{~mol}$ $\mathrm{EG}+0.09 \mathrm{~mol} \mathrm{ChCl} \mathrm{DESs} \mathrm{for} 30$ minutes at $60^{\circ} \mathrm{C}$. The films were a translucent brown colour before insertion into the DES, however following only a few seconds of submersion the films were observed to change from the brown colour to white, characteristic of the $\mathrm{TiO}_{2}$ layer under the HOIP. This result provides an initial indication that the HOIP layers had, in each case, been dissolved. XRD patterns of the three HOIP films on $\mathrm{TiO}_{2}$ coated FTO, both before and after DES stripping, are presented in Figure 3, as well as XRD patterns of the FTO and $\mathrm{TiO}_{2}$ coated FTO for comparison.

The $\mathrm{MAPbI}_{3}$ film has cubic structure with evidence of tetragonal splitting, which has also been observed previously. ${ }^{35-37}$ The presence of $\mathrm{PbI}_{2}$ or other phases of $\mathrm{MAPbI}_{3}$ is minimal to non-existent. The $\mathrm{FAPbI}_{3}$ has been characterised as having a tetragonal structure, with diffraction peaks matching those presented in the literature. ${ }^{13}$ The peaks at approximately $11.4^{\circ}$ and $12.7^{\circ}$ most likely relate to FAPI $-\mathrm{PbI}_{2}-\mathrm{DMSO}$ and $\mathrm{PbI}_{2}(\mathrm{DMSO})_{2}$, respectively. The assignment assumes that this system behaves analogous to that of $\mathrm{MAPbI}_{3}$ in which $\mathrm{MAPbI}_{3}-\mathrm{PbI}_{2}-\mathrm{DMSO}$ and $\mathrm{PbI}_{2}(\mathrm{DMSO})_{2}$ intermediates occur due to incomplete phase transitions. ${ }^{38}$ The $\mathrm{Cl}-\mathrm{MAPbI}_{3}$ has predominantly tetragonal character, consistent with that reported by Eperon et al. ${ }^{18}$ In addition to the aforementioned intermediate peaks at low angle, there exist other minor peaks: those peak at $15.6^{\circ}, 17.0^{\circ}$ and $18.5^{\circ}$ can be attributed to the presence of $\mathrm{MAPbX}_{2}-\mathrm{DMSO}$ intermediates; those at $27.9^{\circ}$ and $28.2^{\circ}$ relate to either $\mathrm{MAPbX}_{2}-\mathrm{DMSO}$ or $\mathrm{PbI}_{2}(\mathrm{DMSO})_{2}$, whilst the peak at $35.0^{\circ}$ relates to $\mathrm{PbI}_{2}(\mathrm{DMSO})_{2} .{ }^{38}$

Diffraction patterns that can be attributed to the HOIPs are clearly observable, however following 30 minutes of stripping in the DES the XRD patterns (in each case) match only those of the $\mathrm{TiO}_{2}$ coated FTO. This result clearly shows that the HOIP films have dissolved into the DES, whereas the FTO and $\mathrm{TiO}_{2}$ remain on the electrode. The SEM images in Figure 3 show the three HOIP films before and after stripping in the DES, and additionally an image of the $\mathrm{TiO}_{2}$ coated FTO before the deposition of a HOIP layer is presented for comparison. It can be seen that prior to the deposition of the HOIP the $\mathrm{TiO}_{2}$ is formed as a fractured film on the FTO surface. Parts (b), (d) and (f) show the $\mathrm{MAPbI}_{3}, \mathrm{FAPbI}_{3}$ and $\mathrm{MAPbI}_{3-\mathrm{x}} \mathrm{Cl}_{\mathrm{x}}$ deposited on the $\mathrm{TiO}_{2}$ coated FTO. Some structure from the $\mathrm{TiO}_{2}$ can still be seen under the $\mathrm{FAPbI}_{3}$, this appears to be due to this HOIP film being thinner than the $\mathrm{MAPbI}_{3}$ and $\mathrm{MAPbI}_{3-\mathrm{x}} \mathrm{Cl}_{\mathrm{x}}$ films. Following the DES stripping of each of the HOIP films, the images in parts (c), (e) and (g) show no evidence of the HOIP layer and the images resemble those of the $\mathrm{TiO}_{2}$ coated FTO prior to the HOIP deposition. There are some differences in the size of the fractured $\mathrm{TiO}_{2}$ islands between each sample, with the size noticeably varying. Rather than being an effect of the stripping process, it is likely that this is due to some slight variation in the $\mathrm{TiO}_{2}$ films prior to the film deposition. Regardless, it can be seen that the HOIP layer has, in each case, clearly been removed following immersion into the DES. The combination of the XRD and SEM results in Figure 3 demonstrate the suitability 
of the DES system to stripping HOIP films from the $\mathrm{TiO}_{2}$ coated FTO layer of a HOIP solar cell, for example, these results show that the remaining $\mathrm{TiO}_{2}$ coated FTO substrate could possibly be reused in the fabrication of a new HOIP PV device, which will be the focus of further study.

\subsection{Selective Removal of Lead from Solvent}

For the electrochemical measurements, powdered HOIP materials have been dissolved into the DES to better simulate the process of metal recovery from an industrial system, where much larger quantities of HOIP would be present in the DES solution than that from a $2 \mathrm{~cm}^{2}$ thin film. Each of the three HOIP powders $\left(\mathrm{MAPbI}_{3}, \mathrm{FAPbI}_{3}\right.$ and $\left.\mathrm{MAPbI}_{3-\mathrm{x}} \mathrm{Cl}_{\mathrm{x}}\right)$ were dissolved in the DES at $60^{\circ} \mathrm{C}$ such that $\mathrm{EG}: \mathrm{ChCl}: \mathrm{HOIP}$ molar ratios of 2:1:0.00057 were achieved. In each case the powder completely dissolved giving a translucent yellow coloured liquid. Cyclic voltammogram (CV) and potentiostatic measurements have been undertaken using tindoped indium oxide (ITO) substrates as the working electrode to study the electrochemistry of $\mathrm{Pb}$ deposition and stripping from each HOIP dissolved in the DES. ITO has been used as the working electrode as it does not undergo any redox reactions in the $\mathrm{DES}$ and deposited $\mathrm{Pb}$ can be easily identified from the substrate during subsequent characterization. Through $\mathrm{CVs}$ and potentiostatic measurements the deposition and stripping processes of $\mathrm{Pb}$ from the DESs can be understood. Figure 4 (a) shows CVs of $\mathrm{Pb}$ deposition and stripping on an ITO working electrode from DESs containing $\mathrm{MAPbI}_{3}, \mathrm{FAPbI}_{3}$ and $\mathrm{MAPbI}_{3-\mathrm{x}} \mathrm{Cl}_{\mathrm{x}}$ as well as a control DES containing no dissolved HOIP.

No oxidation or reduction processes are observed in the control CV, however in all cases where the HOIPs are dissolved in the DES one reduction and one oxidation peak is observed. These peaks are therefore attributed to the deposition of $\mathrm{Pb}$ from the reduction of $\mathrm{Pb}(\mathrm{II})$ in solution to $\mathrm{Pb}$ on the working electrode, and the stripping of $\mathrm{Pb}$ on the working electrode to $\mathrm{Pb}(\mathrm{II})$ in solution by oxidation. The reduction and oxidation peaks are separated by $0.39 \mathrm{~V}, 0.36 \mathrm{~V}$ and $0.37 \mathrm{~V}$ for the $\mathrm{MAPbI}_{3}, \mathrm{FAPbI}_{3}$ and $\mathrm{MAPbI}_{3-\mathrm{x}} \mathrm{Cl}_{\mathrm{x}} \mathrm{DESs}$ respectively. For an electrochemically reversible two electron process the peak-to-peak separation $\Delta \mathrm{E}_{\mathrm{pp}}$ should be $31.8 \mathrm{mV} .^{39}$ The measured values of $\Delta \mathrm{E}_{\mathrm{pp}}$ are much higher than this, which is indicative of an irreversible electrochemical reaction due to higher overpotentials being required for the reduction and oxidation processes. The $\mathrm{Cl}$ $\mathrm{MAPbI}_{3} \mathrm{DES} \mathrm{CV}$ was recorded over a narrower potential window than the $\mathrm{MAPbI}_{3}$ and $\mathrm{FAPbI}_{3} \mathrm{DESs}$ as the current was observed to be very negative at potentials beyond $-0.9 \mathrm{~V}$ vs Ag due to reduction of the ITO.

To compare the diffusion of the $\mathrm{Pb}$ (II) species in each DES solution the Randles-Sevcik equation, modified for an irreversible electrochemical reaction, can be used $^{40}$ :

$$
I_{\max }=\left(2.99 \times 10^{-5}\right) \alpha^{1 / 2} C D^{1 / 2} v^{1 / 2}
$$


$I_{\max }$ is the peak reduction current density in the $\mathrm{CV}, \alpha$ is the transfer coefficient, $C$ is the concentration in solution $\left(2.3 \times 10^{-6} \mathrm{~mol} \mathrm{~cm}^{-3}\right), v$ is the scan rate and $D$ is the diffusion coefficient. By recording CVs at multiple scan rates in the range of $25 \mathrm{mV} \mathrm{s}^{-1}$ to $100 \mathrm{mV} \mathrm{s}^{-1}$ and plotting the square root of the scan rate against the reduction peak current density the diffusion of the $\mathrm{Pb}$ (II) species in each DES can be compared by considering the gradient of a linear fit of the data points, shown in Figure 4 (b). The gradients of the best fit for each of the HOIP-DES solutions have been calculated to be $-0.70 \pm 0.06 \mathrm{~mA} \mathrm{~cm}^{-2}\left(\mathrm{~V} \mathrm{~s}^{-1}\right)^{-1 / 2}$ for the $\mathrm{MAPbI}_{3} \mathrm{DES},-0.76 \pm 0.11 \mathrm{~mA} \mathrm{~cm}^{-2}\left(\mathrm{~V} \mathrm{~s}^{-1}\right)^{-1 / 2}$ for the FAPI DES and $-0.73 \pm 0.08 \mathrm{~mA} \mathrm{~cm}^{-2}\left(\mathrm{~V} \mathrm{~s}^{-1}\right)^{-1 / 2}$ for the $\mathrm{MAPbI}_{3-\mathrm{x}} \mathrm{Cl}_{\mathrm{x}}$ DES. Using the above equation, it can be seen that the gradient of the linear fit is related to $(\alpha \mathrm{D})^{1 / 2}$, therefore, the common gradient for each solution, within experimental error, indicates that the $\mathrm{Pb}(\mathrm{II})$ speciation in each solution is the same, and the diffusion of the $\mathrm{Pb}(\mathrm{II})$ in each solution is consistent.

$\mathrm{Pb}$ films were deposited on the ITO substrates through potentiostatic deposition from each of the HOIP-DESs by applying a potential of $-0.8 \mathrm{~V}$ vs $\mathrm{Ag}$ for 60 minutes. XRD patterns of these films are presented in Figure 4 (c) showing that by potentiostatic deposition $\mathrm{Pb}$ is extracted from the DES solutions and electrodeposited onto the working electrode. The peaks in the XRD patterns can almost all be attributed to the deposited $\mathrm{Pb}$, with only a minor contribution from the $\operatorname{In}_{2} \mathrm{O}_{3}$ peaks from the ITO substrate. High-resolution scanning electron microscopy (HR-SEM) images of the deposited $\mathrm{Pb}$ from each HOIP-DES, as well as an ITO substrate control, are shown in Figure 4 (d)-(g) and indicate that the $\mathrm{Pb}$ deposits as particles on the ITO surface. The larger particles (approximately 100-500 nm) seen in the HR-SEM images are the deposited $\mathrm{Pb}$, whilst the much smaller grains of the ITO (approximately 20-60 nm) can faintly be seen underneath.

\subsection{Complete Lead Extraction}

Electrochemical deposition of $\mathrm{Pb}$ from each of the dissolved HOIP powders was done using a $\mathrm{Pb}$ working electrode in a three-electrode electrochemical cell. Using a $\mathrm{Pb}$ working electrode is highly beneficial as the process electrodeposits dissolved $\mathrm{Pb}$ onto a $\mathrm{Pb}$ electrode and reduces any further steps needed to transfer the deposited metal, meaning it ready for new use in industrial applications in a highly pure form. The HOIPs $\left(\mathrm{MAPbI}_{3}, \mathrm{FAPbI}_{3}\right.$ and $\left.\mathrm{MAPbI}_{3-\mathrm{x}} \mathrm{Cl}_{\mathrm{x}}\right)$ were added to each DES solution such that an EG:ChCl:HOIP mole ratio of 2:1:0.00057 was achieved. Potentiostatic deposition of $\mathrm{Pb}$ from each of the HOIP-DESs was undertaken for 120 hours at $-0.9 \mathrm{~V}$ vs Ag. Inductively coupled plasma mass spectrometry (ICP-MS) measurements of the $\mathrm{Pb}$ concentration in each of the DES solutions, before and after 120 hours of $\mathrm{Pb}$ extraction, are presented in Table 1. It can be seen from the results that for each dissolved HOIP $\geq 98.7 \%$ of the $\mathrm{Pb}$ has been extracted from the solution, with a maximum of $99.8 \% \mathrm{~Pb}$ extraction achieved for the Cl-MAPBI ${ }_{3}$ DES. Dissolving $2 \mathrm{~cm}^{2}$ $\mathrm{MAPbI}_{3}, \mathrm{FAPbI}_{3}, \mathrm{MAPbI}_{3-\mathrm{x}} \mathrm{Cl}_{\mathrm{x}}$ thin films in approximately $21 \mathrm{ml}$ of the $\mathrm{EG}+\mathrm{ChCl} \mathrm{DES}$ yielded $\mathrm{Pb}$ concentrations of $13.3,3.5$ and $5.3 \mathrm{ppm}$ respectively. If this is scaled up based upon the pre-extraction $\mathrm{Pb}$ concentrations in Table 1, then using 1 litre of 2:1 EG $+\mathrm{ChCl}$ would enable the dissolution and extraction of HOIP films in the order of $1 \mathrm{~m}^{2}$. Further to this, the $\mathrm{Pb}$ concentrations in Table 1 do not represent the maximum dissolution of HOIP in the DES, so it is very likely that a higher amount of HOIP, and therefore 
high surface areas of solar cells, could be recycled in a single litre of DES. It is also important to note that by designing and engineering high-throughput electrochemical cells, the time taken to fully extract the lead from the DES would be significantly reduced.

\subsection{The Speciation of Lead}

EXAFS measures x-ray absorption as a function of energy and can be used to determine the arrangement of atoms surrounding the central absorbing atom. It is therefore element specific and is well-suited to the study of metal coordination sites in ionic liquids and molten salts, as illustrated by the review by Hardacre. ${ }^{41}$ The EXAFS signal results from interference between the out-going photoelectron waves and those back-scattered from surrounding atoms and manifests itself as an oscillation in the absorption coefficient at energies greater than that of the absorption edge. By extracting the experimental EXAFS signal and fitting with a theoretically calculated curve based on the EXAFS equation, ${ }^{42}$ the local arrangement of atoms (type, number, and distance up to $\sim 6 \AA^{41}$ ) around the absorbing atom can be elucidated.

EXAFS measurements have been carried out to understand the speciation of the dissolved HOIP in the DES. Plots of the normalised absorption data, fitted k-space EXAFS and fitted pseudo-radial distribution functions from the $\mathrm{MAPbI}_{3}, \mathrm{FAPbI}_{3}, \mathrm{MAPbI}_{3-\mathrm{x}} \mathrm{Cl}_{\mathrm{x}} \mathrm{DES}$ samples are all shown Figure 5. Importantly it can clearly be seen from these plots that there is no significant differences between the data from the three samples. This conclusion is supported by the results of the fitting of the EXAFS (Table 2), which suggests that in all three samples the $\mathrm{Pb}$ cation is surrounded by three chlorine atoms at a distance of $2.65 \AA$. Based on these results, the most likely $\mathrm{Pb}$ species in the DES is $\left[\mathrm{PbCl}_{3}\right]^{-}$. This species has been observed previously in lead(II) chloride ionic liquids. ${ }^{43}$ The speciation of $\mathrm{Pb}$ for each of the three dissolved HOIPs is consistent with the gradients of the Randles-Sevcik plots in Figure 4 (b), which were also the same, within experimental error.

\section{Conclusions}

Three lead-based HOIP materials, $\mathrm{MAPbI}_{3}, \mathrm{FAPbI}_{3}$ and $\mathrm{MAPbI}_{3-\mathrm{x}} \mathrm{Cl}_{\mathrm{x}}$ have solvated by a DES and the lead recovered and successfully electrochemically. Potentiostatic lead deposition from the HOIP-DES solutions has been shown through XRD and HR-SEM on an ITO working electrode, and thin films of each lead HOIP have been successfully stripped from $\mathrm{TiO}_{2}$ coated FTO substrates. Higher concentrations of powdered forms of each HOIP have been dissolved in the EG-ChCl DES with the Pb subsequently extracted at rates of up to 99.8\% using a $\mathrm{Pb}$ working electrode. EXAFS measurements have identified the atoms solvating the dissolved $\mathrm{Pb}$ to be $\mathrm{Cl}$, forming a $\left[\mathrm{PbCl}_{3}\right]^{-}$species. For all three dissolved HOIPs the same speciation was observed in the DES. The combination of these results demonstrates a proof of principle of lead recycling for HOIP based solar cells. The need to develop environmentally friendly and low cost recycling of these materials is of critical importance if they are to ever find application in the end-user marketplace for solar power generation. We believe that DES based recycling is a hugely effective method to recover the lead from HOIP based solar 
cells, both for future market end-of-life disposal as well as a convenient method for the disposal of the increasing number of test cells currently being generated in research laboratories globally. Finally, we believe that this approach could be more widely adopted for all lead-based energy materials.

\section{Acknowledgements}

D.J.P. acknowledges support from the Royal Society (UF100105). C.G.P acknowledges support from EPSRC for a DTA Studentship and an EPSRC Impact Acceleration Award (EP/K503733/1). We thank Diamond Light Source for access to beamline B18 (SP12198-1) that contributed to the results presented here.

\section{References}

1. Hodge, A. T. Roman Aqueducts \& Water Supply. (Duckworth, 2002).

2. Planté, G. Nouvelle pile secondaire d'une grande puissance. Séances Acadi. Sci. 50, 640 (1860).

3. Needleman, H. L. The removal of lead from gasoline: historical and personal reflections. Environ. Res. 84, 20-35 (2000).

4. Pei, Y. et al. Convergence of electronic bands for high performance bulk thermoelectrics. Nature 473, 66-69 (2011).

5. Pei, Y., LaLonde, A., Iwanaga, S. \& Snyder, G. J. High thermoelectric figure of merit in heavy hole dominated PbTe. Energy Environ. Sci. 4, 2085-2089 (2011).

6. Lee, M. M., Teuscher, J., Miyasaka, T., Murakami, T. N. \& Snaith, H. J. Efficient hybrid solar cells based on meso-superstructured organometal halide perovskites. Science. 338, 643-7 (2012).

7. Green, M. A., Ho-Baillie, A. \& Snaith, H. J. The emergence of perovskite solar cells. Nat. Photonics 8, 506-514 (2014).

8. Jeon, N. J. et al. Compositional engineering of perovskite materials for high-performance solar cells. Nature 517, 476-480 (2015).

9. Kim, H.-S. et al. Lead iodide perovskite sensitized all-solid-state submicron thin film mesoscopic solar cell with efficiency exceeding 9\%. Sci. Rep. 2, 1-7 (2012).

10. Etgar, L. et al. Mesoscopic $\mathrm{CH}_{3} \mathrm{NH}_{3} \mathrm{PbI}_{3} / \mathrm{TiO}_{2}$ heterojunction solar cells. J. Am. Chem. Soc. 134, 17396-17399 (2012).

11. Xing, G. et al. Long-range balanced electron- and hole-transport lengths in organic-inorganic $\mathrm{CH}_{3} \mathrm{NH}_{3} \mathrm{PbI}_{3}$. Science. 342, 344-7 (2013).

12. Stranks, S. D. et al. Electron-hole diffusion lengths exceeding 1 micrometer in an organometal trihalide perovskite absorber. Science. 342, 341-4 (2013).

13. Eperon, G. E. et al. Formamidinium lead trihalide: a broadly tunable perovskite for efficient planar heterojunction solar cells. Energy Environ. Sci. 7, 982 (2014). 
14. Koh, T. M. et al. Formamidinium-containing metal-halide: An alternative material for near-IR absorption perovskite solar cells. J. Phys. Chem. C 118, 16458-16462 (2014).

15. Eperon, G. E. et al. Efficient, semitransparent neutral-colored solar cells based on microstructured formamidinium lead trihalide perovskite. J. Phys. Chem. Lett. 6, 129.138 (2015).

16. Liu, M., Johnston, M. B. \& Snaith, H. J. Efficient planar heterojunction perovskite solar cells by vapour deposition. Nature 501, 395 (2013).

17. Ball, J. M., Lee, M. M., Hey, A. \& Snaith, H. J. Low-temperature processed meso-superstructured to thin-film perovskite solar cells. Energy Environ. Sci. 6, 1739 (2013).

18. Eperon, G. E., Burlakov, V. M., Docampo, P., Goriely, A. \& Snaith, H. J. Morphological control for high performance, solution-processed planar heterojunction perovskite solar cells. Adv. Funct. Mater. 24, 151-157 (2014).

19. Hodes, G. \& Cahen, D. Photovoltaics: Perovskite cells roll forward. Nat. Photonics 8, 87-88 (2014).

20. Needleman, H. Lead poisoning. Annu. Rev. Med. 55, 209-22 (2004).

21. Canfield, R. L. et al. Intellectual impairment in children with blood lead concentrations below 10 microg per deciliter. N. Engl. J. Med. 348, 1517-26 (2003).

22. Needleman, H. L. Bone lead levels and delinquent behavior. JAMA J. Am. Med. Assoc. 275, 363 (1996).

23. Dietrich, K. N., Ris, M. D., Succop, P. a, Berger, O. G. \& Bornschein, R. L. Early exposure to lead and juvenile delinquency. Neurotoxicol. Teratol. 23, 511-8 (2001).

24. Gottesfeld, P. \& Pokhrel, A. K. Review: Lead exposure in battery manufacturing and recycling in developing countries and among children in nearby communities. J. Occup. Environ. Hyg. 8, 520-32 (2011).

25. Abbott, A. P., Capper, G., Davies, D. L., Rasheed, R. K. \& Tambyrajah, V. Novel solvent properties of choline chloride/urea mixtures. Chem. Commun. 70-71 (2003). doi:10.1039/b210714g

26. Abbott, A. P., Boothby, D., Capper, G., Davies, D. L. \& Rasheed, R. K. Deep eutectic solvents formed between choline chloride and carboxylic acids: versatile alternatives to ionic liquids. J. Am. Chem. Soc. 126, 9142-7 (2004).

27. Abbott, A. P., Capper, G., Davies, D. L., Rasheed, R. K. \& Shikotra, P. Selective extraction of metals from mixed oxide matrixes using choline-based ionic liquids. Inorg. Chem. 44, 6497-9 (2005).

28. Abbott, A. P., Capper, G., Davies, D. L., McKenzie, K. J. \& Obi, S. U. Solubility of metal oxides in deep eutectic solvents based on choline chloride. J. Chem. Eng. Data 51, 1280-1282 (2006).

29. Smith, E. L., Abbott, A. P. \& Ryder, K. S. Deep eutectic solvents (DESs) and their applications. Chem. Rev. 114, 11060-11082 (2014).

30. Abbott, A. P., Capper, G., Davies, D. L., Rasheed, R. K. \& Tambyrajah, V. Quaternary ammonium zinc- or tin-containing ionic liquids: Water insensitive, recyclable catalysts for Diels-Alder reactions. Green Chem. 4, 24-26 (2002). 
31. Hu, S. et al. Direct conversion of inulin to 5-hydroxymethylfurfural in biorenewable ionic liquids. Green Chem. 11, 873 (2009).

32. Singh, B., Lobo, H. \& Shankarling, G. Selective N-alkylation of aromatic primary amines catalyzed by bio-catalyst or deep eutectic solvent. Catal. Letters 141, 178-182 (2011).

33. Haerens, K., Matthijs, E., Chmielarz, A. \& Van der Bruggen, B. The use of ionic liquids based on choline chloride for metal deposition: A green alternative? J. Environ. Manage. 90, 3245-52 (2009).

34. Kumar, R. V, Yang, J. \& Sonmez, S. Relevance of reaction of lead compounds with carboxylic acid in lead recovery from secondarysSources. J. Powder Metall. Min. 2, 3-7 (2013).

35. Bhachu, D. S. et al. Scalable route to $\mathrm{CH}_{3} \mathrm{NH}_{3} \mathrm{PbI}_{3}$ perovskite thin films by aerosol assisted chemical vapor deposition. J. Mater. Chem. A 1-3 (2014).

36. Zhao, Y. \& Zhu, K. Charge transport and recombination in perovskite $\left(\mathrm{CH}_{3} \mathrm{NH}_{3}\right) \mathrm{PbI}_{3}$ sensitized TiO2 solar cells. J. Phys. Chem. Lett. 4, 2880-2884 (2013).

37. Baikie, T. et al. Synthesis and crystal chemistry of the hybrid perovskite $\left(\mathrm{CH}_{3} \mathrm{NH}_{3}\right) \mathrm{PbI}_{3}$ for solid-state sensitised solar cell applications. J. Mater. Chem. A 1, 5628 (2013).

38. Jeon, N. J. et al. Solvent engineering for high-performance inorganic-organic hybrid perovskite solar cells. Nat. Mater. 13, 897-903 (2014).

39. Compton, R. G. \& Banks, C. E. Understanding Voltammetry. (Imperial College Press, 2011).

40. Bard, A. J. \& Faulkner, L. R. Electrochemical Methods: Fundamentals and Applications. (John Wiley and Sons, 2001).

41. Hardacre, C. Application of EXAFS to molten salts and ionic liquid technology. Annu. Rev. Mater. Res. 35, 29-49 (2005).

42. Stern, E. A., Sayers, D. E. \& Lytle, F. W. Extended x-ray-absorption fine-structure technique. III. Determination of physical parameters. Phys. Rev. B 11, 4836-4846 (1975).

43. Coleman, F. et al. Lead(II) chloride ionic liquids and organic/inorganic hybrid materials--a study of chloroplumbate(II) speciation. Dalt. Trans. 42, 5025-35 (2013).

44. Oropeza, F. E., Harmer, J., Egdell, R. G. \& Palgrave, R. G. A critical evaluation of the mode of incorporation of nitrogen in doped anatase photocatalysts. Phys. Chem. Chem. Phys. 12, 960-969 (2010).

45. Oropeza, F. E., Davies, B., Palgrave, R. G. \& Egdell, R. G. Electronic basis of visible region activity in high area Sn-doped rutile $\mathrm{TiO}_{2}$ photocatalysts. Phys. Chem. Chem. Phys. 13, 7882-7891 (2011).

46. Wu, Y. et al. Retarding the crystallization of $\mathrm{PbI}_{2}$ for highly reproducible planar-structured perovskite solar cells via sequential deposition. Energy Environ. Sci. 7, 2934 (2014).

47. Raga, S. R. et al. Influence of air annealing on high efficiency planar structure perovskite solar cells. Chem. Mater. 27, 1597-1603 (2015).

48. Ravel, B. \& Newville, M. ATHENA, ARTEMIS, HEPHAESTUS: Data analysis for X-ray absorption spectroscopy using IFEFFIT. J. Synchrotron Radiat. 12, 537-541 (2005). 
49. Ravel, B., Cockayne, E., Newville, M. \& Rabe, K. Combined EXAFS and first-principles theory study of Pb1-xGexTe. Phys. Rev. B 60, 14632-14642 (1999).

50. Mao, J. \& Graedel, T. E. Lead in-use stock. J. Ind. Ecol. 13, 112-126 (2009).

51. Hong, S., Candelone, J. P., Patterson, C. C. \& Boutron, C. F. Greenland ice evidence of hemispheric lead pollution two millennia ago by greek and roman civilizations. Science. 265, 1841-1843 (1994).

52. Nevin, R. How lead exposure relates to temporal changes in IQ, violent crime, and unwed pregnancy. Environ. Res. 83, 1-22 (2000).

53. Baur, W. H. \& Khan, A. A. Rutile-type compounds. IV. $\mathrm{SiO}_{2}, \mathrm{GeO}_{2}$ and a comparison with other rutile-type structures. Acta Crystallogr. Sect. B Struct. Crystallogr. Cryst. Chem. 27, 2133-2139 (1971).

54. Horn, M., Schwerdtfeger, C. F. \& Meagher, E. P. Refinement of the structure of anatase at several temperatures. Zeitschrift für Krist. 136, 273-281 (1972).

55. Bouad, N., Chapon, L., Marin-Ayral, R.-M., Bouree-Vigneron, F. \& Tedenac, J.-C. Neutron powder diffraction study of strain and crystallite size in mechanically alloyed PbTe. J. Solid State Chem. 173, 189-195 (2003).

56. Marezio, M. Refinement of the crystal structure of $\operatorname{In}_{2} \mathrm{O}_{3}$ at two wavelengths. Acta Crystallogr. 20, 723-728 (1966). 


\section{Tables}

Table 1: Parts per million of $\mathrm{Pb}$ in HOIP-DESs before and after $\mathrm{Pb}$ extraction by electrodeposition.

\begin{tabular}{cccc}
\hline \hline Solution & \multicolumn{2}{c}{ Pb Parts per Million } & Percentage Extracted \\
& Pre-Extraction & Post-Extraction & $(\%)$ \\
\hline $\mathrm{MAPbI}_{3} \mathrm{DES}$ & 432.80 & 1.37 & 99.7 \\
$\mathrm{FAPbI}_{3} \mathrm{DES}$ & 540.34 & 6.86 & 98.7 \\
$\mathrm{MAPbI}_{3-\mathrm{x}} \mathrm{Cl}_{\mathrm{x}} \mathrm{DES}$ & 616.49 & 1.43 & 99.8 \\
\hline \hline
\end{tabular}

Table 2: Local environment of the $\mathrm{Pb}$ dissolved in the $\mathrm{DES}$ as determined by the fitting of the EXAFS data. $\mathrm{R}$ is the distance, $\mathrm{N}$ is the number of neighbours and $\sigma^{2}$ is the mean-square disorder in $\mathrm{R}$.

\begin{tabular}{cccccc}
\hline \hline Sample & Ligand & $\mathrm{R} / \AA$ & $\mathrm{N}$ & $\sigma^{2} / \AA^{2}$ & R-factor \\
\hline $\mathrm{MAPbI}_{3} \mathrm{DES}$ & $\mathrm{Cl}$ & $2.649(11)$ & $2.7(3)$ & $0.0110(15)$ & 0.0172 \\
$\mathrm{FAPbI}_{3} \mathrm{DES}$ & $\mathrm{Cl}$ & $2.653(9)$ & $2.8(3)$ & $0.0116(13)$ & 0.0102 \\
$\mathrm{MAPbI}_{3-\mathrm{x}} \mathrm{Cl}_{\mathrm{x}} \mathrm{DES}$ & $\mathrm{Cl}$ & $2.659(11)$ & $2.9(3)$ & $0.0117(15)$ & 0.0158 \\
\hline \hline
\end{tabular}




\section{Figures}
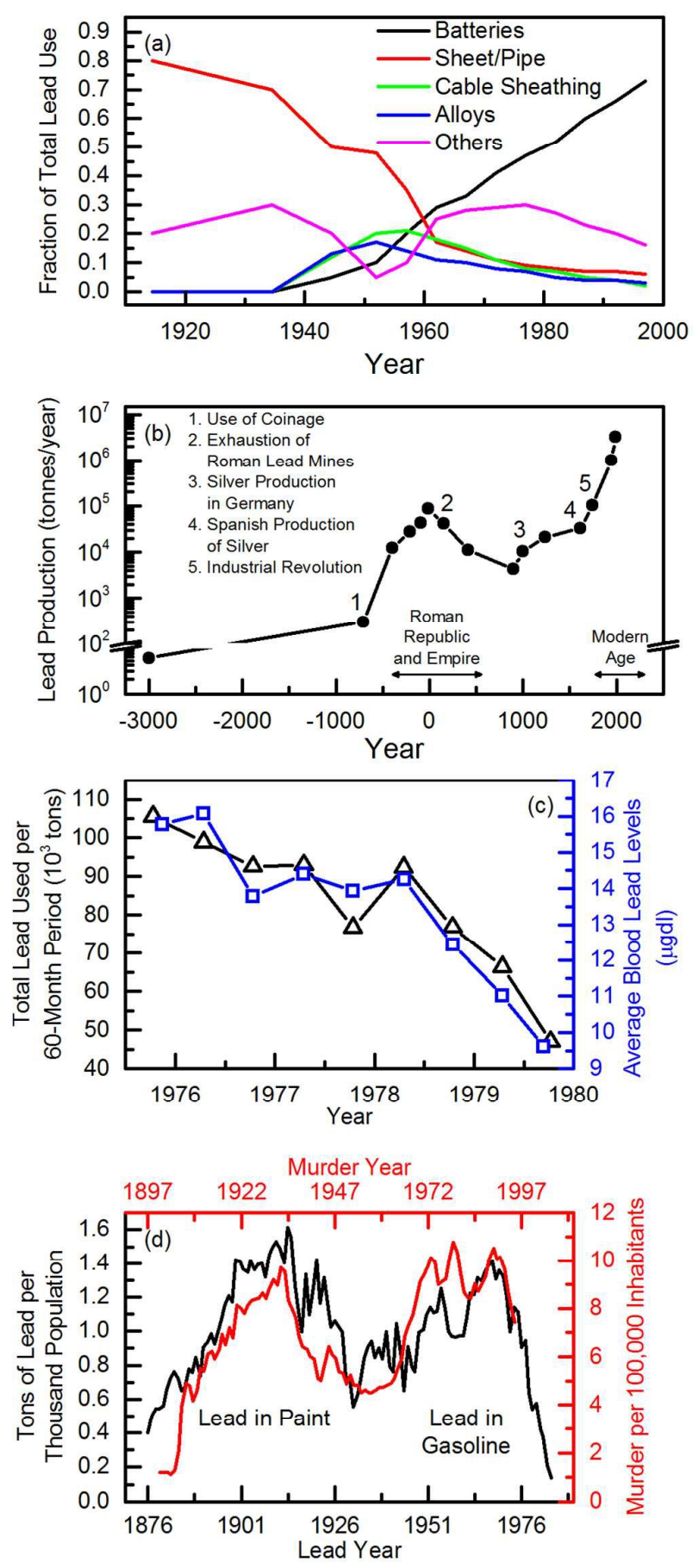

Figure 1: (a) The applications of $\mathrm{Pb}$ in industry in the 20th Century (adapted from Reference ${ }^{50}$ ), (b) lead production rates in the past 5000 years (adapted from Reference ${ }^{51}$ ), (c) the correlation between the removal of $\mathrm{Pb}$ from petrol and the decrease in blood lead content (adapted from Reference ${ }^{3}$ ), and (d) the correlation between the use of lead in paint, and the use of lead petrol, with murder rate (adapted from Reference ${ }^{52}$ ). 


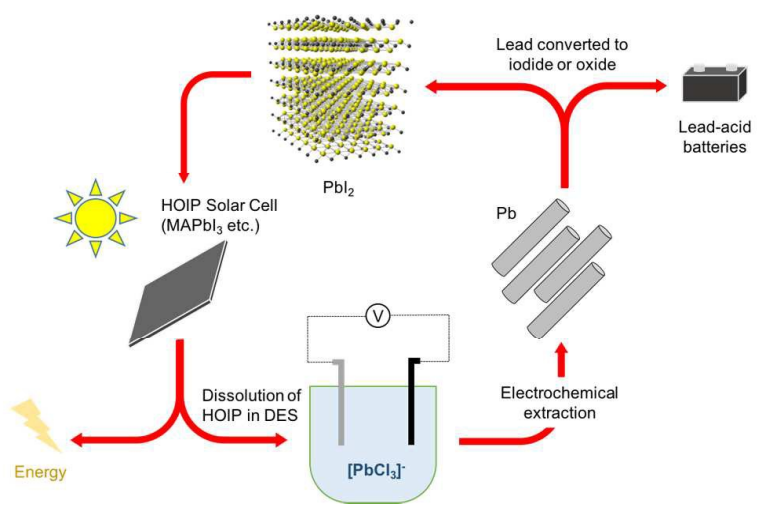

Figure 2. Schematic of the deep eutectic solvent based electrochemical recycling process, showing route to regenerate HOIP material, or feed metallic lead back into the supply chain. 


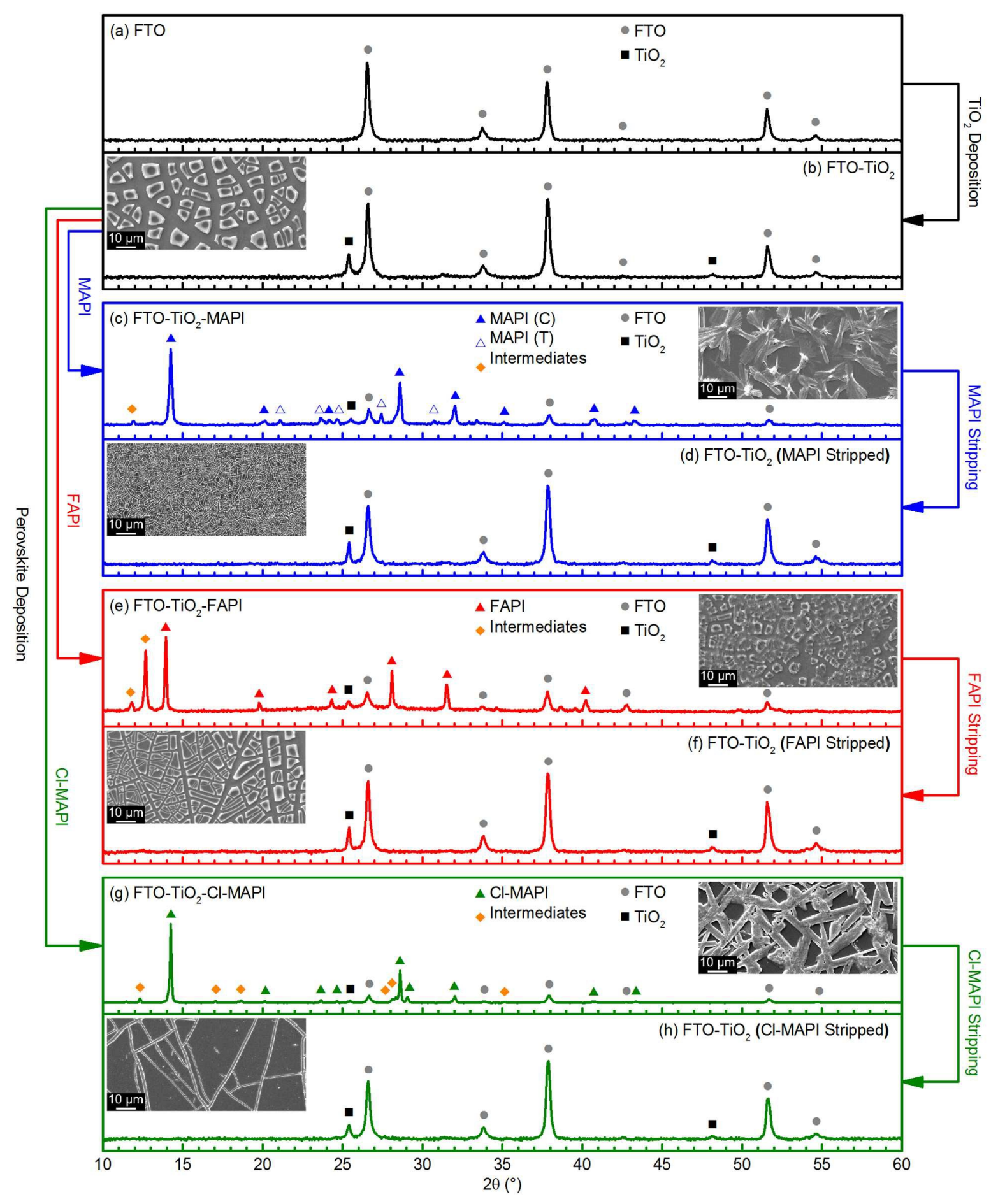

Figure 3: XRD patterns and inset SEM images of (a) the FTO substrate, (b) the $\mathrm{TiO}_{2}$ coated FTO substrate, and on the $\mathrm{FTO}-\mathrm{TiO}_{2}$ substrates the $\mathrm{MAPbI}_{3}$ film (c) before and (d) after stripping, the $\mathrm{FAPbI}_{3}$ film (e) before and (f) after stripping, and the $\mathrm{MAPbI}_{3-\mathrm{x}} \mathrm{Cl}_{\mathrm{x}}$ film (g) before and (h) after stripping. The peaks labelled as "intermediates" are remnants of the synthesis process and are discussed further in the text. The XRD peak assignment has been undertaken using the following references: $\mathrm{SnO}_{2}(\mathrm{FTO}),{ }^{53} \mathrm{TiO}_{2},{ }^{54} \mathrm{MAPbI}_{3},{ }^{35-37} \mathrm{FAPbI}_{3},{ }^{13}$ $\mathrm{MAPbI}_{3-\mathrm{x}} \mathrm{Cl}_{\mathrm{x}} \cdot{ }^{18}$ 

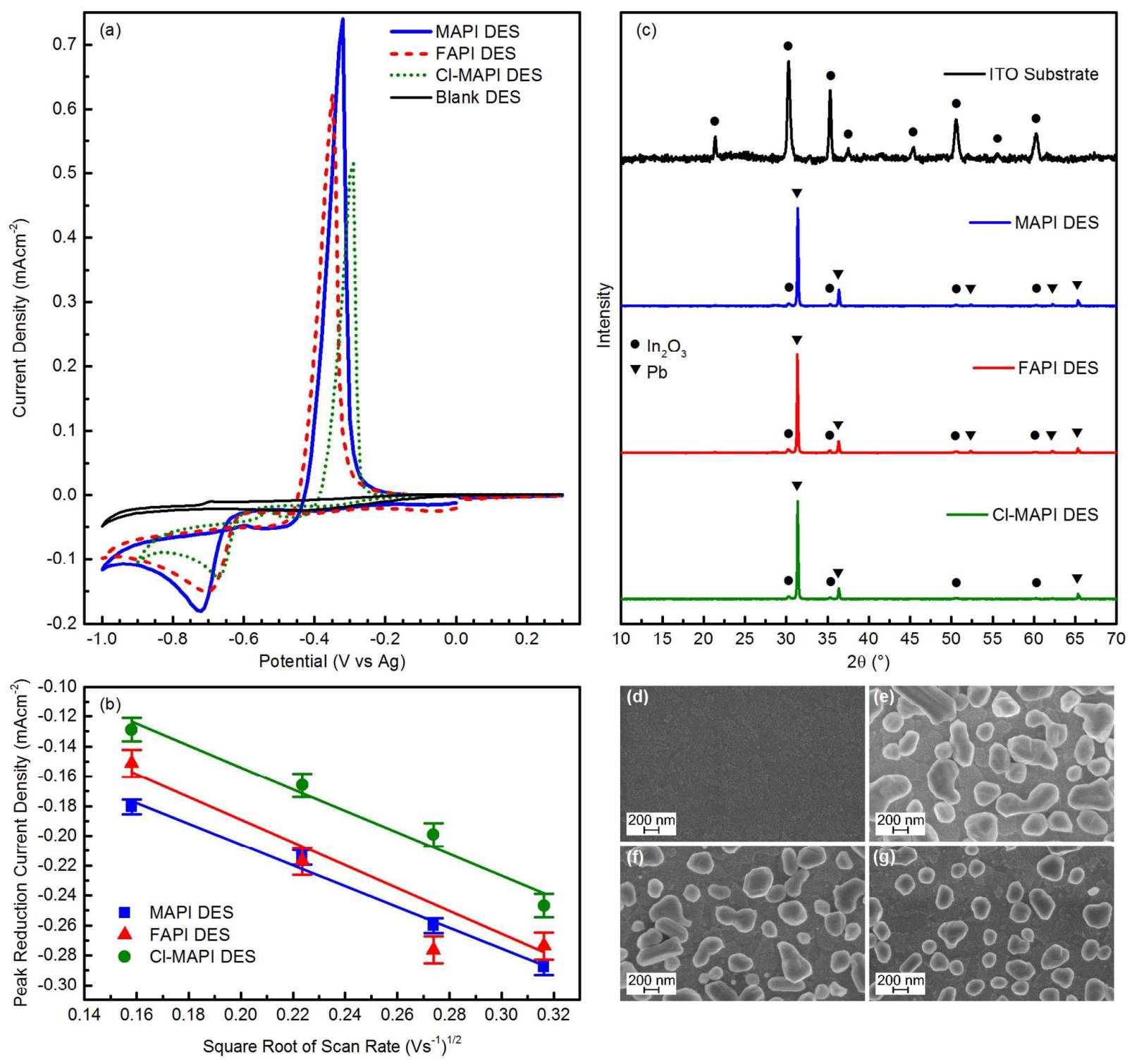

Figure 4: (a) CVs of $\mathrm{Pb}$ deposition and stripping from $\mathrm{MAPbI}_{3}, \mathrm{FAPbI}_{3}$ and $\mathrm{MAPbI}_{3-\mathrm{x}} \mathrm{Cl}_{\mathrm{x}} \mathrm{DESs}$, and a control DES containing no dissolved HOIP, with an ITO working electrode, recorded at $25 \mathrm{mV} \mathrm{s}^{-1}$. (b) Randles-Sevcik plots of the square root of the scan rate as a function of the reduction peak potential, with linear fitting applied, for each of HOIP dissolved in the DES, recorded using an ITO working electrode. The outlying data point for the $\mathrm{FAPbI}_{3} \mathrm{DES}$ at $75 \mathrm{mV} \mathrm{s}^{-1}$ has not been included in the best fit calculation. (c) XRD patterns of $\mathrm{Pb}$ potentiostatically deposited at $-0.8 \mathrm{~V}$ vs Ag for 1 hour on ITO from each HOIP-DES, and a blank ITO substrate as a control. The XRD peaks have been assigned using References ${ }^{55}$ and ${ }^{56}$ for $\mathrm{Pb}$ and $\mathrm{In}_{2} \mathrm{O}_{3}$ (ITO) respectively. (d) HR-SEM image of an ITO substrate prior to Pb deposition. (e), (f) and (g) show $\mathrm{HR}-\mathrm{SEM}$ images of $\mathrm{Pb}$ deposited from the $\mathrm{MAPbI}_{3}, \mathrm{FAPbI}_{3}$ and $\mathrm{MAPbI}_{3-\mathrm{x}} \mathrm{Cl}_{\mathrm{x}} \mathrm{DESs}$ respectively. 

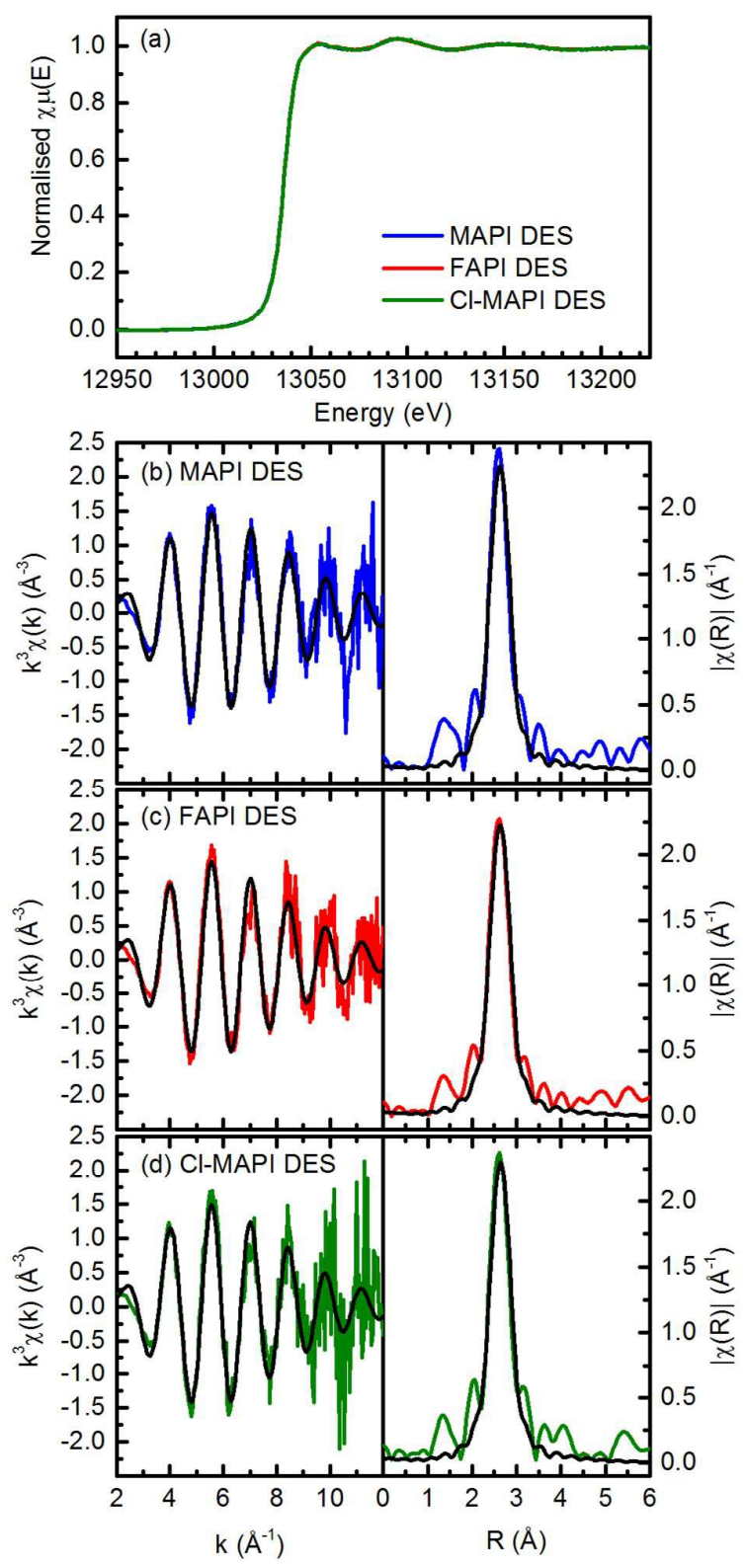

Figure 5: (a) X-ray absorption edge of the HOIP samples dissolved in the ChCl-EG DES. (b)-(d) Fitted data of the $k$-space EXAFS curves and pseudo-radial distribution functions of the (b) $\mathrm{MAPbI}_{3} \mathrm{DES}$, (c) $\mathrm{FAPbI}_{3}$ DES and (d) $\mathrm{MAPbI}_{3-\mathrm{x}} \mathrm{Cl}_{\mathrm{x}}$ DES. The left panels show the $k$-space data and the right panels show the realspace data. The experimental data is shown in blue, red and green for the $\mathrm{MAPbI}_{3}, \mathrm{FAPbI}_{3}$ and $\mathrm{MAPbI}_{3-\mathrm{x}} \mathrm{Cl}_{\mathrm{x}}$ DES respectively, with the fits in black. 